\title{
The Relation of Aeration to the Growth and Activity of Roots and its Influence on the Ecesis of Plants in Swamps. ${ }^{1}$
}

BY

\author{
H. F. BERGMAN. \\ With three Graphs in the Text.
}

THE effect of various factors on the form and growth of roots has been 1 repeatedly investigated by experimenters during the past fifty years, although little attention seems to have been paid to the effect of the surrounding medium on their functional activity. This is particularly true with reference to their oxygen supply. Very recently, however, Livingston and Free (14, p. I82) have shown that 'the first effect of oxygen deprivation is an interference with the absorption of water by the roots'. Accordingly, in determining the effect of various factors on the growth and distribution of swamp plants, it was decided to make a special study of aeration in such habitats. In so far as possible, exact data have been secured as to the oxygen and carbon dioxide content of lake and swamp waters under normal conditions. The influence of other factors, however, has not been neglected.

The work was in progress about three years. The field work was done mostly during the summer months in the northern part of Minnesota. The experimental work was carried on during the winters of I9I4-I5 and 1915-16 in the University greenhouse.

\section{Effects of Aeration on Submerged Roots.}

Experiments with a number of plants have been performed in the greenhouse to determine the effect of root submergence, through limitation of the air supply, as a factor in the development and activity of roots. In the course of these experiments the plants were grown in the same kinds of soil and under the same conditions of temperature. The kind of water or amount of air supplied were the only factors varied.

Seedlings of bean (Phaseolus vulgaris var.), plants of Impatiens balsamina, Pelargonium sp., Cyperus alternifolius, Ranunculus abortivis and

1 Accepted by the University of Minnesota in partial fulfilment of the requirements for the Degree of Doctor of Philosophy.

[Annals of Botany, Vo1. XXXIV. No. CXXXIII. January, 1920.] 


\section{Bergman.-Relation of Aeration to Growth and Activity of}

$R$. sceleratus, potted in soil, were placed in vessels of water so that the surface of the water came above the level of the tops of the pots. Duplicate sets in swamp water were also set up. In two days the plants of Impatiens began to wilt. In three days they were badly wilted, and in four days were wilted beyond recovery. On the fourth or fifth day plants of Pelargonium and Phaseolus began to wilt, and if left in water two or three days longer the leaves turned yellow and dropped. Cyperus and Ranunculus showed no ill effects, but grew vigorously with their roots submerged.

Later the same experiment was repeated, but as soon as the plants showed signs of wilting air or oxygen was supplied. It was found in all cases that the plants, if not too badly wilted, could be restored to normal condition and could be kept growing indefinitely if aeration were continued. After a week or ten days all plants developed new roots at or near the surface of the water, after which the plants were able to live without having oxygen or air artificially supplied. No difference in the behaviour of plants in tap-water as compared with those in swamp water could be noted. For this reason, and also because of the difficulty of obtaining swamp water during the winter months, the use of swamp water in later experiments was discontinued.

\section{Effects of excluding Air from Roots in Soil.}

Two plants of Pelargonium, potted in soil, were set up in the following manner. The leafy stems were passed through the mouth of a wide-mouthed bell-jar so that the stem and leaves came out into the air while the roots in the pot were under the bell-jar. The mouth around the stems and the base of the bell-jar were sealed with wax so as to be air-tight. Carbon dioxide was then passed through to replace the air. This was repeated morning and night to maintain an atmosphere of pure carbon dioxide. A watering device was so arranged that water could be added without admitting air at the same time. A slight wilting of one plant was apparent on the second day following, and on the third day the wilting was very evident. Wilting of the second plant did not begin until the fourth day, but on the fifth day it had become very pronounced. The leaves on both plants after wilting became yellow and soon dropped. The yellowing and dropping of leaves continued until the test was ended, ten days after it was begun. The soil was found to be normally moist at the end of the test.

A plant of Impatiens balsamina was arranged as just described for Pelargonium, and the air replaced by carbon dioxide. On the second day the plant was slightly wilted, and on the morning of the third day badly wilted. The plant was removed at noon on the third day. On the following day the plant appeared as if badly frosted. This plant never recovered. 


\section{Experiments with Ramunculus.}

The following autumn the experiments were repeated on a more extensive scale. Six plants each of Ramunculus abortivus and $R$. sceleratus, potted in soil, were placed in vessels of water so that the roots were completely submerged. Three plants of each were left in ordinary garden soil as controls. After three months the plants were all in good condition. It was found, however, that the plants with submerged roots had produced more and larger leaves and considerably more extensive root systems than those in moist soil. The roots in all cases, whether submerged or not, were distributed throughout the soil.

\section{Experiments with Corn (Zea) and Beans.}

Eighteen pots each of corn and beans were planted in sets of three under the following conditions: in garden soil as a check; in soil, roots submerged; in peat; in peat, roots submerged; in Sphagmum; and in Sphagnum, roots submerged. After the plants were up the cotyledons of the beans were removed. They were then allowed to grow two or three days before the test was begun. Swamp water was used in watering except for plants in soil, for which tap-water was used. The plants were allowed to grow three months. At the end of this time the plants of both corn and beans growing in soil had made the best development of leaves and roots. The roots extended throughout the soil, tending to mat at the bottom, and were well provided with root-hairs. Bean plants in soil, with roots submerged, developed as many leaves as those in soil not submerged. The leaves soon dropped, however, so that at the end of the test the plants with submerged roots had only one or two leaves each. Corn in soil, with roots submerged, showed little or no retardation in the extent of shoot development. Root development after submergence was less extensive and entirely superficial in both beans and corn.

Beans grown in moist peat or Sphagmum developed nearly as much foliage as those grown in soil. The plants, however, were not quite as tall nor as robust. Root development was not as extensive as in plants grown in soil. The roots extended throughout the peat or Sphagnum, tending to mass at the bottom of the pots. Root-hairs were present in abundance. Beans and corn when grown in either peat or Sphagnum, with the roots subinerged, showed a marked inhibition in growth. The stems were more slender and dwarfed. The leaves were usually less numerous and were reduced in size as compared with plants in soil, peat, or Sphagnum, the roots of which had not been submerged. Root development was poor. The roots of corn grew much more extensively than those of beans, which seldom reached out to the edge of the pots. They were always less extensive than those of plants in soil with the roots submerged. 


\section{Experiments with Impatiens balsamina.}

Two plants of Impatiens; potted in soil, were placed in vessels of water so that the roots were completely submerged. Several plants of Philotria were placed in the water surrounding one of the pots. Aeration in this case was provided by the evolution of oxygen from the photosynthetic activity of Philotria. The second plant was in water without Philotria. Three days later the first plant was in good condition, while the second was wilted. The wilting of the second plant continued for two days more, when it was in such bad condition that it was removed. The first plant was still in good condition. This plant was left two months, during which time it lost about four or five leaves. Ten days after submergence of the roots new roots were coming out along the stem at the surface of the water. These continued to develop, and an examination later showed that the lower roots had died, so that only the superficial ones were alive.

The experiment with Impatiens was repeated later, six plants being used. All were potted in garden soil. Four of them were placed in water with the roots fully submerged. Of these four, one was aerated by bubbling air continuously through the water. Another was aerated by putting some Spirogyra in the water in which the potted plant was placed. The other two were not aerated. The fifth plant was grown in very wet soil. This was done by placing the pot in a basin of water so that only the bottom of the pot was in direct contact with the water. The sixth plant was grown in moist garden soil as a check. In three days the plants with the roots submerged in unaerated water were badly wilted and werê removed. All other plants were in good condition. In five days the plant in water aerated by bubbling air through the water showed a slight yellowing of some of the leaves, but no wilting. The plant aerated by Spirogyra was slightly wilted. This was assumed to be due to continued cloudiness, on account of which the liberation of oxygen by Spirogyra was reduced to such an extent that the water was insufficiently aerated. On the following day both plants in aerated water were badly wilted, the one in water aerated by Spirogyra being in the worse condition. Ten days after the experiment was begun the plants were still living, but each had lost several leaves. The remaining leaves were not wilted. Roots were beginning to develop along the stem at the surface of the water in both plants. The plants grown in soil wet by capillarity, and in moist garden soil, were in good condition.

The experiment was allowed to run three weeks. All the plants except the two in unaerated water survived. Those with roots submerged in aerated water lost several leaves in the first week or ten days. After developing roots at the surface of the water, however, they began to grow again, and apparently normally. Roots below the surface died. Root-hairs were 
developed on some of the roots in aerated water. In the plant in soil wet by capillarity roots also developed at the surface. In this case the upper roots made the greatest growth, but all the lower roots were living. In moist garden soil root development was extensive, reaching to all parts of the pot with an abundant development of root-hairs.

\section{Experiments with Pelargonium and Coleus.}

A similar experiment was carried out with Pelargonium. On plants with the roots submerged and not aerated, the leaves began to turn yellow in ten days or two weeks. Shortly afterwards the leaves dropped. The behaviour of the roots of Pelargonium was similar to that observed in Impatiens. In all cases where the roots were submerged, whether or not the water was aerated, new roots developed at the surface, while the submerged roots died. This was also found to be true of the roots of Pelargonium in soil wet by capillarity, although with Impatiens the lower roots remained alive. After the development of surface roots the plants again began to grow and produce new leaves. Root development in ordinary moist soil was abundant. Pelargonium was found to be less responsive than Impatiens in that it did not show wilting as clearly or as quickly. Loss of colour was the first sign of distress. Soon after changing colour the leaves usually dropped.

Plants of Coleus Blumei potted in soil, with the roots submerged, showed signs of distress in one or two days. The first evidence was the wilting of the leaves. The leaves after remaining in a more or less wilted condition a few days dropped off, until only two or three small leaves near the top of the stem remained. After ten days or two weeks new roots were always found to have developed from the stem at the surface of the water. Plants in moist soil developed normally.

\section{Experiments with Vicia Faba.}

An experiment with Vicia Faba was tried as follows: Seeds were planted in batteries of six pots each containing garden soil, peat, and Sphagnum respectively. As soon as the seedlings had broken through the ground the cotyledons were removed from two plants in each set. From each battery of six, two plants with cotyledons and one with cotyledons removed were placed in vessels of water so that the roots were fully submerged. The other three pots of each battery of six were kept moist, but never to saturation. In four or five days all plants, the roots of which had been submerged, began to wilt. This condition continued for a week or more in varying degree according to the temperature of the greenhouse. In all cases, however, the plants lived. The plants were permitted to grow ten weeks; at the end of this time it was noted that the plants in soil with the roots not submerged had grown most, those in Sphagnum least, and 
those in peat intermediate. In submerged plants less difference was noticeable, although the same order seemed to hold. Loss of leaves did not occur in any of the plants. Removal of the cotyledons caused a general reduction in the amount of growth. This was least noticeable in plants grown in moist garden loam, and quite evident in plants grown in peat or Sphagnum. The reduction in growth was most noticeable in plants grown in peat or Sphagnum with the roots submerged.

Plants grown in moist soil showed the greatest development of roots. The form of the root system of plants grown in either peat or Sphagmum was similar, and in extent of growth nearly equal to those in soil. The roots of all plants under conditions of submergence were similar. The lower roots were dead, and new roots had developed from the stem at the surface of the ground. The depth of penetration was never more than an inch below the water surface. The longer and more branched roots usually came even nearer the surface. No root-hairs were present on submerged roots, although abundantly present on others.

\section{Effect of Root Submergence on Transpiration.}

The following experiment was performed to ascertain the effect of root submergence on transpiration: Two plants of Pelargonium, potted in soil, were placed in aluminium pots, the tops of which were covered with

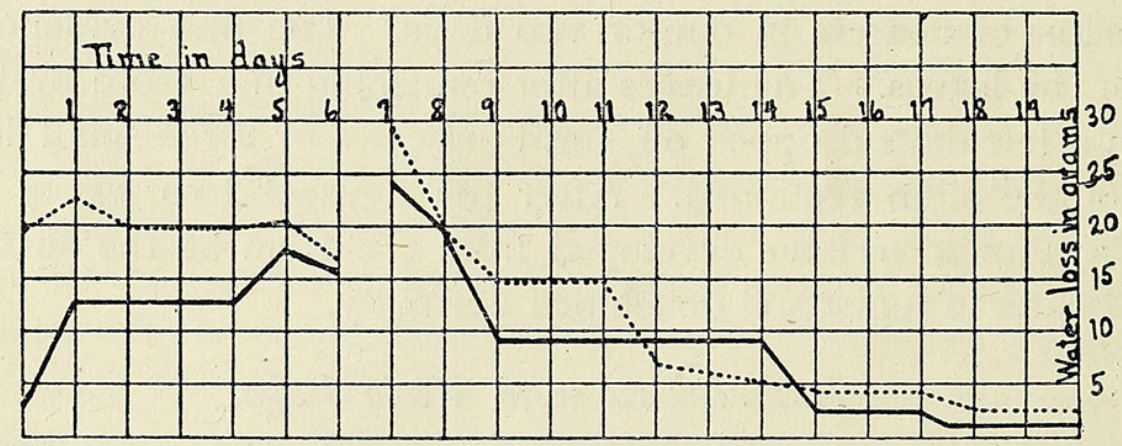

FIG. I. Graphs showing comparative rates of transpiration of two plants of Pelargonium, the broken line for the one in moist soil and the solid line for the one in soil submerged. The break on the sixth day marks the time at which the roots were submerged. On the eleventh day the leaves began to turn yellow, and by the fourteenth day were beginning to drop off. A decrease in the rate of transpiration is evident on both of these days.

sheet rubber to prevent evaporation from the surface of the soil. The plants were weighed each day for a week. The roots were then submerged and the daily weighing continued. The results are shown in the accompanying graph (Fig. I). On the day following root submergence it was found that the rate of transpiration had greatly increased. The rate, however, fell off rapidly, and after two days had fallen to a point lower than when growing in moist soil. Recording instruments showed that the humidity and temperature conditions in the geenhouse had not changed. 
The reduced rate, then, is not to be explained by lower temperature and higher humidity. After two days of the reduced rate of transpiration, the leaves began to turn yellow. From this time the average transpiration rate dropped still lower until at the end of ten days after the roots had been submerged the transpiration rate per day averaged $7 \cdot 3 \mathrm{grm}$. for one plant, and $9 \mathrm{grm}$. for the other. This average rate was maintained three days, at which time the plants began to shed their leaves. In the nine days following, in which weighings were continued, the average daily rate of transpiration was reduced to $2.8 \mathrm{grm}$. for one plant, and $\mathrm{I} .5 \mathrm{grm}$. for the other. It is to be observed that when the roots of plants had been submerged a decrease in the average daily rate of transpiration soon followed. It is to be noted, further, that this decreased average daily rate of transpiration

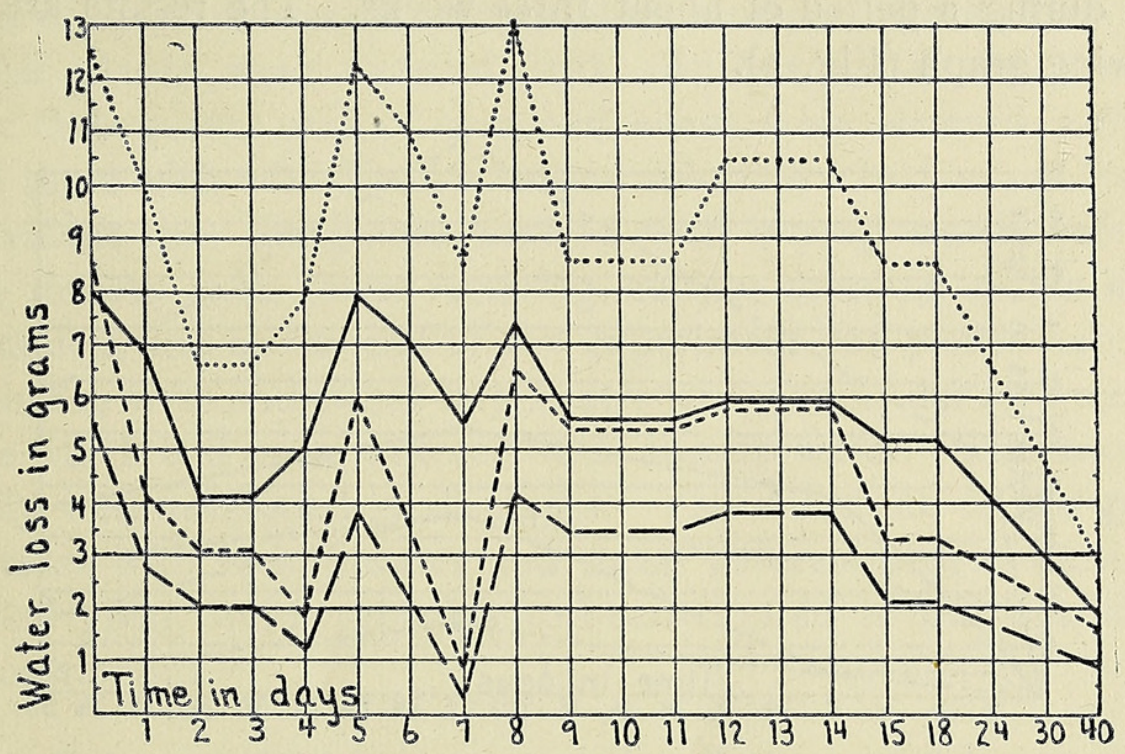

FIG. 2. Comparative transpiration of two seedlings of Quercus macrocarpa. The dotted line represents a plant in moist soil, the line of long dashes a plant in submerged soil. Leaf area of former, 100 sq. $\mathrm{cm}$.; of the latter, 64.27 sq. $\mathrm{cm}$. The line of short dashes represents the rate of transpiration of the plant with the smaller leaf area based on $100 \mathrm{sq} . \mathrm{cm}$. leaf surface; the heavy solid line represents the transpiration rate of the plant with $100 \mathrm{sq} . \mathrm{cm}$. leaf area based on the same leaf area as the plant in submerged soil.

continued two or more days before the manifestation of any evidence of injury to the plant. These facts indicate clearly that transpiration is greater than absorption. The shedding of leaves is to be regarded as a compensation for the reduced ability to absorb by reduction of the transpiration surface.

Two seedlings of Quercus macrocarpa were potted in garden soil in aluminium pots. The roots of one were submerged, while the other was allowed to grow in moist soil. The pots were covered with rubber tissue to prevent surface evaporation, and weighings made. The results are shown in the accompanying graph (Fig. 2).

The plant with the roots in moist soil had a leaf area of $100 \mathrm{sq} . \mathrm{cm}$., and the plant with submerged roots had a leaf area of $64.27 \mathrm{sq} . \mathrm{cm}$. In 
order to make a comparison of the rate of transpiration of the two plants, the rate of the latter was calculated on the basis of $100 \mathrm{sq} . \mathrm{cm}$. and of the former on the basis of $64.27 \mathrm{sq} . \mathrm{cm}$. of leaf area, and the corresponding curves plotted. It is to be noted that the rate of transpiration for the plant with roots submerged is lower than either of the calculated rates. Since the actual value probably lies somewhere between the two calculated rates, it seems fair to assume that the difference between the calculated rate and the observed rate for the plant with submerged roots is brought about by submergence.

Later two other seedlings of Quercus macrocarpa were added to the first two. Both of the new plants had the roots submerged and were covered in the same way that the others were. Weighings were made at intervals during a period of about three weeks. The results are shown in the following graph (Fig. 3).

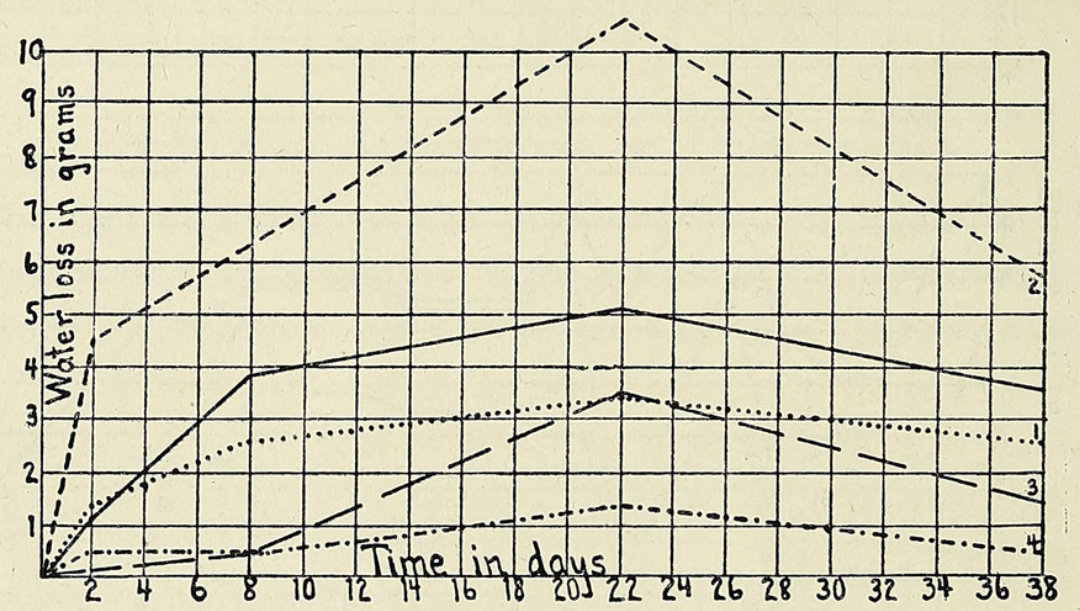

FIG. 3. Comparative rates of transpiration of seedlings of Quercus macrocarpa in moist and in submerged soil. No. 2, in moist soil, leaf area $100 \mathrm{sq}$. cm.; Nos. 1, 3, and 4 in submerged soil. Leaf area: No. I, 64.27 sq. $\mathrm{cm}$; No. $3,48.34$ sq. cm.; No. $4,70.0$ sq. $\mathrm{cm}$. The heavy solid line represents the average rate of the three plants based on the same leaf area as No. 2 in moist soil.

The average transpiration is shown for each plant during the intervals between weighings. The plants were of different sizes and with different leaf areas. No. 2, which was grown in moist soil, had a leaf area of $100 \mathrm{sq} . \mathrm{cm}$. The other three plants had the roots submerged. Their leaf areas in square centimetres were as follows: No. I, 64.27 ; No. $3,48.34$; No. $4,70.0$. In order to make a comparison, a curve for the average transpiration of the three plants calculated on the basis of $100 \mathrm{sq} . \mathrm{cm}$. of leaf area was drawn. When calculated on equivalent leaf areas the average transpiration of the three plants with roots submerged was much lower than that of plant No. 2, the roots of which were not submerged. Plant No. I had the highest rate of transpiration of any of the plants with submerged roots. Even if the transpiration rate of this plant were calculated on the basis of 100 sq. $\mathrm{cm}$, the leaf area of plant No. 2, the calculated rate would 
still be considerably lower than that of No. 2. The second trial with Quercus macrocarpa thus shows that the rate of transpiration per unit area of leaf surface in plants with roots submerged is much reduced in comparison with the rate of transpiration of plants the roots of which have not been submerged.

\section{Comparison of the Effect of Swamp Water and Nutrient Solution on the Grozeth of Plants.}

To compare the effect of swamp water and nutrient solution on the growth of plants under equal conditions of aeration, six pots of corn and six of beans were planted in washed, white quartz sand. The cotyledons of the beans were removed as soon as the first leaves began to expand. The endosperm of the corn was also removed as soon as the first leaf began to unroll. All plants were watered with distilled water for three days. Thereafter three plants each of corn and beans were watered with swamp water and three each with Sachs's culture solution. In four or five days it became evident that the plants watered with swamp water were making less rapid growth than those receiving culture solution. This difference was maintained, and at the end of the experiment the plants watered with culture solution were somewhat larger, stronger, and of darker green colour than those which had been watered with swamp water. The root system was equally well developed in all plants. The difference in the growth of plants watered with swamp water and those watered with culture solution was not very great, and is probably to be attributed to the lack of certain mineral constituents.

\section{Effect of Philotria on the Gas Content of Water.}

In determining the amount of air dissolved, an apparatus similar to that described in Dennis's translation of Hempel's Gas Analysis was used. In the first analyses a flask containing one litre was used, but later this was replaced by one containing two litres. Samples were boiled from three to five minutes. The technical method of analysis was used. Descriptions of this method are to be found in Hempel's Gas Analysis, in Lunge's Technical Gas Analysis, and in other texts. Duplicate analyses were run in nearly every case. The results were found to check within 0.2 to 0.3 c.c.

The following analyses show the effect of placing Philotria in water with good illumination. No. I is tap-water which had stood several days in the laboratory; No. 2, tap-water with Philotria, analysis made early in the forenoon; No. 3, tap-water with Philotria, analysis made in the afternoon after several hours' exposure to good light. Duplicate analyses are given in each case. 
TABLE I.

Gas Content per Litre of Water with and without Philotria.

\begin{tabular}{|c|c|c|c|c|}
\hline No. & Kind of Water. & $\begin{array}{l}\text { Carbon } \\
\text { Dioxide. }\end{array}$ & Oxygen. & Nitrogen. \\
\hline & & c.c. & c.c. & c.c. \\
\hline I & Standing tap & $2 \cdot 8$ & $5 \cdot 4$ & $12 \cdot 6$ \\
\hline 2 & & $2 \cdot 6$ & $5 \cdot 6$ & 12.4 \\
\hline 3 & Tap, with Philotria, forenoon & $2 \cdot 8$ & $5 \cdot 4$ & $\begin{array}{r}12 \cdot 3 \\
12 \cdot 6\end{array}$ \\
\hline $\begin{array}{l}4 \\
5\end{array}$ & afternoon & $\begin{array}{l}2 \cdot 6 \\
0.6\end{array}$ & $\begin{array}{l}5 \cdot 0 \\
8 \cdot 2\end{array}$ & $\begin{array}{l}12 \cdot 0 \\
13 \cdot 0\end{array}$ \\
\hline 7 & ", & 0.8 & $7 \cdot 8$ & $12 \cdot 8$ \\
\hline
\end{tabular}

From this it is to be noted that the oxygen and carbon dioxide content are not affected by Philotria during the night. During daylight, on the other hand, the carbon dioxide is decreased and the oxygen content is increased. Accordingly the value of Philotria as a means of aerating water is established by these analyses. Other analyses, the figures of which are not presented, show that in cloudy weather Philotria has little effect on the carbon dioxide or oxygen content. This accounts for the wilting noted during cloudy weather in plants with submerged roots in the experiments with Impatiens when Philotria was used for aerating the water.

The effect of Philotria in water on the carbon dioxide and oxygen content was tried another time. A large glass jar was filled with water and a handful of Philotria plants thrown in. The jar was set near a south window so as to receive the best possible light. Analyses were made the next day. The first analysis was at I 0.0 a.m., the second at I I.O a.m., and the third at 11.30 a.m. The results are given in the following table:.

TABLE II.

Gas Content per Litre of Water with Philotria.

$\begin{array}{ccccc}\begin{array}{c}\text { Sample } \\ \text { Number. }\end{array} & \begin{array}{c}\text { Time } \\ \text { taken. }\end{array} & \begin{array}{c}\text { Carbon } \\ \text { Dioxide. }\end{array} & \text { Oxygen. } & \text { Nitrogen. } \\ & & \text { c.c. } & \text { c.c. } & \text { c.c. } \\ \text { I } & \text { Io a.m. } & 1 \cdot 1 & 6 \cdot 2 & 12 \cdot 2 \\ 2 & \text { I0.30 a.m. } & 0 \cdot 8 & 7 \cdot 0 & 12 \cdot 2 \\ 3 & \text { II a.m. } & 0 \cdot 5 & 7 \cdot 4 & 12 \cdot 4\end{array}$

It is to be noted here also, as in Table I, that the presence of Philotria in good light causes a decrease in the amount of carbon dioxide and an increase in the amount of oxygen.

\section{Gas Content of Swamp Water.}

During the summer of 1916 , at Hubert, Minnesota, a series of analyses of lake and swamp waters was made. The lake water was from Lake Hubert near the shore in water about two feet deep. Other samples were 
taken in the swamp bordering on Mud Lake. Part of the samples were taken in the Carex-Calamagrostis associes, and the others in the LarixPicea associes. All swamp samples were taken in areas in which Sphagnum and other mosses were abundant. A third series of samples was taken from Henderson's bog, north of Lake Hubert. One sample was taken in the Carex associes and the other two below Sphagmum in the Chamaedaphne-Andromeda associes. The results are presented in the following table:

TABLE III.

Gas Content per Litre of Water from Various Associes.

Source.

Hubert Lake

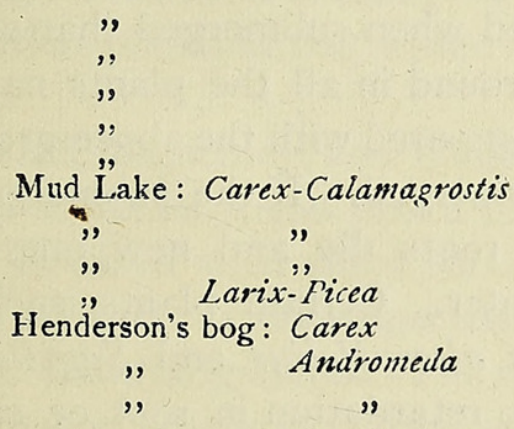

Sample Carbon
Number. Dioxide.

c.c.
$I \cdot 0$
$I \cdot 4$
$1 \cdot 2$
$1 \cdot 2$
$1 \cdot 2$
$1 \cdot 0$
$5 \cdot 8$
$6 \cdot 0$
$6 \cdot 0$
$8 \cdot 4$
$8 \cdot 4$
$9 \cdot 8$
$10 \cdot 2$

Oxygen.

c.c.
$7 \cdot 6$
$7 \cdot 2$
$7 \cdot 4$
$7 \cdot 6$
$7 \cdot 6$
$7 \cdot 8$
$3 \cdot 2$
$3 \cdot 0$
$3 \cdot 0$
$2 \cdot 8$
$4 \cdot 6$
$3 \cdot 9$
$3 \cdot 8$

Nitrogen.

The field analyses were made with the burette only; the solutions being introduced into the burette. Under the conditions the results are not as accurate as those made in the laboratory with pipettes. Comparison of the results, however, with analyses in the laboratory shows that the errors are not more than twice those of laboratory analyses, and accordingly they may be used in comparing results.

It is to be noted from the figures here given that a marked difference exists between the air content of a lake and that of a swamp. Hubert is a spring-fed lake with cold water and a clean gravelly or sandy bottom. The bottom where the samples were taken was of very coarse gravel or pebbles. The water is well supplied with oxygen. When a lake becomes converted into a swamp, a very evident decrease of oxygen occurs with a marked increase in carbon dioxide content. The oxygen content falls off to half or less that of lake or tap water. This undoubtedly is a very important factor in retarding the growth and activity of roots of plants which do not have air-conducting systems. The sample from the Carex zone of Henderson's bog was taken just at the edge where Carex was invading the Castalia associes. The oxygen content there is somewhat higher than it is in later stages. The high carbon dioxide content is to be explained by the decomposition of organic matter. Any lake which contains a large amount of vegetation is usually found to be low in oxygen and 


\section{Bergman.-Relation of Aeration to Growth and Activity of}

high in carbon dioxide content. Birge and Juday (2) show that such conditions prevail in Wisconsin lakes with considerable organic matter on the bottom. They also show (1.c., p. 5I) that under certain conditions lake water may show a supersaturation of oxygen.

The apparently high nitrogen content is due to the fact that considerable quantities of methane are present in swamps, but the quantity was not determined. In making the analyses the residue after absorption by potash and pyrogallol was regarded as nitrogen. For this reason the nitrogen content of swamp waters always runs too high.

\section{Discussion of RESUlts.}

\section{Effect of Root Submergence on Development.}

Experiments with corn, beans, horse bean, and other plants have shown that the roots of land plants are less developed when submerged than when in moist soil. The part of the plant above ground in all the plants named also undergoes a slight reduction in size as compared with the above-ground parts of plants the roots of which are not submerged. If the submergence be prolonged, the more deeply submerged roots die and new ones are developed at or near the surface of the water. Certain plants, such as Ranunculus abortivus, R. sceleratus, Cyperus alternifolius, and Sagittaria, when grown with roots submerged showed no retardation in root or shoot development. On the contrary, a better development of roots and of foliage was noted when the roots were submerged than when growing in moist garden soil. Wacker $(25$, p. 82$)$ in experimenting with the growth of aquatic plants in moist soil obtained similar results. A retardation in the growth of land plants in water has been observed by Sachs (19), Mer (16), Schwartz (22), Wacker (25), Kraus (13), and others. Perseke (17) and Schwartz (22) found that growing land plants with the roots submerged caused a great reduction in the development of root-hairs, and that in many instances no root-hairs were formed.

\section{Effect of Root Submergence on Absorption.}

The absorbing capacity of roots is of vital importance, and very directly and effectively influences the development of the plant. Although it has been repeatedly shown that root submergence causes a retardation in root development, little or nothing has been done, apparently, to determine the effect of root submergence on absorption. In experiments performed by the writer an inhibition in the absorbing capacity of submerged roots is indicated by the etiolation and loss of leaves which soon followed submergence of the roots. This is shown by the graphs (pp. I 8-20), which give the comparative rates of transpiration per unit area of leaf surface of plants of Pelargonium and secdlings of Quercus macrocarpa with roots submerged, 
and of others with the roots in moist soil. The results of these experiments indicate that transpiration is greater than absorption, and that the shedding of leaves is to be regarded as a compensation for reduced ability to absorb by a reduction of the transpiring surface.

\section{The Effect of Aeration on Submerged Roots.}

Arker $(1$, p. 63$)$ found that the rate of root growth of Lupinus albus and Helianthus anmus could be increased by passing a current of air through water or soil. He also found that roots of plants in water readily take up oxygen in solution. Kraus (13) shows that the percentage of germination of seeds and the rate of growth of seedlings of land plants in the early stages of development can be greatly increased by supplying oxygen to the water in which the seeds or seedlings are submerged. Dachnowski (5, p. 314) observed a stunting of roots in cultures of wheat, corn, bean, elm, and other plants in bog water. Aeration, he found, remedied the stunting effect.

Hall, Brenchley, and Underwood (11, p. 298), in an experimental study of soil solutions, found that a better root development and far better growth were obtained with silver sand and kaolin than with fine sand, silt, or in water culture. It was suspected that differences in aeration of the roots might be the disturbing factor. The correctness of this supposition was established by growing barley in culture solutions aerated once a day and aerated continuously. The latter gave much the better root development, and also the better growth of leaves and stems.

Hole (12), as a result of the study of the reproduction of Shorea robusta, came to the conclusion that the failure of reproduction was due to poor aeration, and states (p. 80) that when proper aeration was provided the injurious effects were quickly dissipated.

Experiments of the writer also show that when aeration is provided the development of roots under submergence is not much, if at all, retarded as compared with the growth of roots in moist soil. No essential difference was to be observed in the behaviour of plants with the roots submerged in swamp water as compared with other plants of the same kind with the roots in tap-water. In either case symptoms of distress were manifested in equal degree in the same period of time, and in either case the plants recovered with equal promptness when air was supplied. In the experiment described on p. 2I, only a slight difference in the size and vigour of the plants watered with nutrient solution as compared with those watered with swamp water was observed. The plants in both cases were under the same conditions of aeration, so that differences of size or vigour cannot be ascribed to that cause. The slightly poorer growth noted in the plants watered with swamp water was probably due to a lack of potash or nitrates or both. 


\section{The Amount of Oxygen required for Growth.}

Dehérain and Vesque $(6$, p. 340$)$ by their experiments established the fact that if the roots were deprived of oxygen the plant itself soon perished. The amount of oxygen necessary for growth is very small according to Wieler, (26) but varies in different plants. He found the maximum growth to take place in Vicia Faba with 5-6 per cent. of oxygen. For Helianthus 3 per cent. was the optimum amount. With other plants a retardation took place between I4-I 6 per cent. according to the plant. Vöchting $(24$, p. 94) found that a reduction of pressure to 3 per cent. or below caused the production of hairs on the roots of potato tubers to cease. Wacker $(25$, p. 85), in growing seedlings of Vicia Faba and Helianthus annuus under bell-jars in which the atmospheric pressure had been reduced to one-tenth, found a slight retardation in the root development as compared with plants under full atmospheric pressure. The difference was not great, however, and he could not state with certainty that the retardation was due to the reduction in the amount of oxygen.

Recently Cannon and Free $(4$, p. 178$)$, in experimenting with various plants, have shown that they behave very differently in their response to a diminution of the oxygen supply to roots. Coleus they found to be injured with a small decrease of oxygen below that of normal atmosphere. Nerium, on the other hand, is quite resistant to oxygen deprivation and first showed injury after 26 days in an atmosphere of pure nitrogen. They also found that with Salix 'entire deprivation of oxygen appeared to be without injurious effect'.

\section{The Oxygen Content of Various Substrata.}

The oxygen content of the water or other substratum in which the plants are growing is an important factor in determining not only the growth and activity of the roots but of the entire plant. Whether the amount present is sufficient for the plant's needs, and the manner of maintaining or replenishing the supply, are other points to be considered. Boussingault and Lewy (3) and von Fodor (7) found the oxygen content of soils to be somewhat lower than that of atmospheric air. Russell and Appleyard (18) also found the same to be true. In soils under usual conditions there are abundant spaces between soil particles through which air can diffuse, so that a supply of oxygen is available to the roots at all times.

When the soil is saturated, or has water present in excess, the air is driven out of the interstices of the soil. The only oxygen then available is that in solution in the water. The greater part of a unit volume of soil is occupied by soil particles, leaving only a small volume which can be occupied by water. Water, moreover, contains a relatively small amount of oxygen. Accordingly it is evident that much less oxygen is available in 
a supersaturated soil than in water alone, and a much greater difference exists between a supersaturated soil and an ordinary soil. This accounts for the observations of Wacker (25, p. 109) that seedlings of Vicia Faba and Lupinus albus grown in supersaturated soil showed as compared with the amount of growth in moist soil a greater retardation even than when grown in water. He observed, however, that with frequent changing of water the retardation was somewhat less.

Oxygen diffuses slowly through water, so that the supply is not quickly replenished by diffusion alone. The investigations of Kraus (13) show that boiled water in vessels sealed to exclude the air completely prevents the germination of seeds. Boiled water exposed to air after eight days gave a greatly reduced percentage of germination as compared with seeds in unboiled water. The amount of root growth was also much less in the former than in the latter. He also shows that submergence at greater depths decreases the percentage of germination of seeds, which he explains by the slowness of diffusion of oxygen. In open water agitation by wind and convection currents tend to replenish the oxygen supply. These factors are probably more important than diffusion. In supersaturated soil convection currents and surface agitation are not făctors, or are of very little importance.

The very small amount of oxygen in the substratum of peat or Sphagnum swamps is also to be explained by the difficulty of replenishing the supply from the air. In peat or Sphagnum substrata the presence of living Sphagnum and of the accumulated remains of dead plants prevents surface agitation of the water and convection currents by which the oxygen content could be maintained. There is also another factor which operates here, and which does not affect the aeration of ordinary soils, or only to a slight extent. This factor is the presence of partly decomposed remains of Sphagnum and other plants, which absorb the oxygen and prevent its penetration into the deeper-lying parts of the substratum. Dachnowski (5, p. 372) calls attention to the reducing power of peat, and shows that it is greatest in the central zone and decreases towards the outside.

In comparing the growth of various plants in soil, peat, and Sphagmum, with the roots submerged, it was noticed that the roots of plants in peat were usually more retarded in growth than those in soil, and that those in Sphagnum showed the greatest retardation. A similar relative reduction in growth of parts above ground was observed. An explanation for this did not at first suggest itself. Later it was found, in the experiment described on p. 2I, that only a slight difference in the size and vigour of shoots was noticeable between plants watered with swamp water and those watered with culture solution. The roots, moreover, were equally well developed in all plants. The difference could not have been due to a lack of aeration, since oxygen was available to the roots at all times. The difference was 
assumed to be due to the lack of one or more mineral constituents. In view of these facts it seems very probable that the much greater reduction in growth of plants in peat or Sphagnnm, with roots submerged, was due to a lack of aeration. This conclusion is further confirmed by the fact that analyses show the oxygen content of the water of peat and Sphagnum substrata to be much lower than that of lake or tap water. The reducing power of peat and Sphagnum also operates to prevent a replenishment of the oxygen supply from the air. It has also been shown that, if aeration is provided, plants grown with the roots submerged in either swamp or tap water show little or no reduction in growth and no essential difference in behaviour as compared with that of plants grown in moist soil.

\section{The Relation of Roots to the Water-level with Reference to the Character of the Plant.}

Plants growing in swamps may be hydrophytic, mesophytic, or xerophytic in character. Many writers regard Scirpus, Equisetum, Funcus and similar plants as bog xerophytes on account of the absence of leaves and general external appearance. The ratio of transpiration to absorption is the important factor in determining the character of a plant. Scirpus has been shown by Sampson and Allen (21, p. 49) to be a typical hydrophyte in its rate of transpiration. And as Groom (10) has shown, in the case of Larix decidua, some so-called xerophytes transpire more rapidly than some mesophytes. The only plants which are unquestionably bog xerophytes are the Ericads. Gates (8) concludes that winter evaporation is fundamentally responsible for their xerophytic character.

Proximity of location in a swamp does not necessarily mean similarity or identity of conditions either for the roots or for parts above ground. In fact, conditions for different layers are very different, as both Yapp (27) and Sherff (23) have pointed out. The conditions for root growth above and below the water-level are also very different. Hydrophytes with their extensively developed air-conducting systems are able not only to withstand root submergence, but to make better growth than in moderately moist soil. Absorption is not retarded, and however great the water loss from aerial parts it is readily replaced by absorption of water by the roots. Hence there is no need for structural modifications of the aerial organs to prevent water loss.

Plants with roots above the water-level are usually low-growing, and consequently more or less protected from excessive water loss. The absorbing capacity of the roots is little or not at all reduced ordinarily, since good aeration is provided and other factors are not very adverse. Such plants are usually mesophytic in character. However, in dry years or during dry periods of the summer they may be subject to more severe conditions. The upper layers of the substratum become dry, or at least do 
not furnish enough available water for plants on account of the great waterretaining power of Sphagnum. For this reason plants with roots above water may show more or less severe wilting on the hotter days. If the drought becomes too prolonged or too intense some of these plants may perish.

Plants, such as the Ericads, which are not protected by taller vegetation may be subjected to very great water loss. The roots of these plants are generally not extensive. They ordinarily grow above the water-level or not far below it. They may, however, endure submergence for some time without apparent injury. During the summer the Sphagnum on which the bog heaths grow may have but little available water because of the lowering of the water-level and the great ability of Sphagnum to retain water, or for other reasons. Therefore, water in sufficient amounts for the needs of the plants might be difficult to obtain. Gates $(8$, p. $45 \mathrm{I})$ states that in such cases 'The xerophytic adaptations ... materially aid by lessening the demand upon root absorption'. In winter, with continued water loss from the leaves at a time when replacement by absorption is very difficult if not impossible, the xerophytic structures are very valuable in reducing the rate of transpiration.

The character and position of the roots with reference to the waterlevel has been shown to be directly correlated with the need of aeration. In securing adequate aeration the plant may undergo structural modification by the development of aerenchyma, or the roots may develop above the water-level. In the latter case, however, the amount of water available is involved. If the plants are more or less protected by taller vegetation, or if the substratum does not become too dry, sufficient water is available to replace the loss by transpiration in mesophytes, and they are able to persist. - On the other hand, a lowering of the water-level, a cold substratum, or other factors which retard absorption, combined with atmospheric factors which bring about a high rate of transpiration, make it impossible for mesophytes to persist. Only the Ericads with their strongly xerophytic leaf-structures are able to endure such conditions. Accordingly the presence of hydrophytes, mesophytes, and xerophytes in swamps is to be explained by local differences in the habitat. These differences, according to the nature of the adjustment of the roots to the water-level, which influences the amount of water available, affect the ratio of absorption to transpiration and determine the character of the plant.

\section{The Relation of Aeration to Ecesis.}

Many plants are able to establish themselves in habitats with an excess of water. Fruits of Almus incana, Betula pumila, Panicularia americana, Rumex britannica, and Scirpus cyperinus germinated, and the seedlings were able to establish themselves on Sphagnum when the water-level was kept just at the surface of the Sphagnum. Seedlings of Rumex were able 
to grow when submerged to a depth of one inch. Fruits of Typha, Sagittaria, and Alisma germinate and develop readily under water. It was observed, however, that fruits of Alisma and Sagittaria in jars of water with clean sand at the bottom failed to develop beyond the early stages of germination. The oxygen and carbon dioxide content of the water was not determined, and consequently it is not known to what extent the concentration of these gases may have been responsible for the failure of the seedlings to develop.

Carex pseudocyperus, Dulichium arundinaceum, Ribes spp., Salix spp., and many other plants germinate readily on hummocks of Sphagnum or on mounds of peat, but fail to germinate if submerged. Seedlings of Andromeda glaucophylla, Kalmia glauca, and Ledum groenlandicum have been found on Sphagnum or peat above the water-level. It seems probable, therefore, that seedlings of these plants are not able to develop under prolonged root submergence. Glück (9) found that the seeds of many plants possessed the ability to germinate and grow under water. Other seeds failed to germinate if covered to a depth of half an inch or less. Kraus (13) has shown that the germination of seeds of land plants may be brought about by aerating the water. Differences are to be observed in the behaviour of various seeds in this respect. Some require less oxygen than others.

The behaviour of roots of seedlings shows the same relation to aeration that is shown by the roots of older plants. Only those plants with welldeveloped aerenchyma are able to establish themselves in habitats with an excess of water. If the water-level is below the surface slightly, many plants are able to invade and become established. The roots of such plants remain near the surface. Periods of hot, dry weather during the summer, which cause the upper layers of the substratum to become dry, may then result in the death of seedlings with shallow root systems. Thus it is evident that the need for adequate aeration for the germination of seeds and the development of seedlings is an important factor in ecesis. It determines in a large measure the character of the invaders in swamps.

\section{Conclusions.}

(I) Roots of land plants do not live under prolonged submergence. The submerged roots die and new ones are developed from the stem at the surface of the water. This occurs whether the plants are grown in loam, peat, or Sphagnum.

(2) Land plants grown in peat or Sphagnum show an evident reduction in growth of the entire plant when the roots are submerged. This is little or not at all apparent in plants grown in soil with submerged roots.

(3) Reduction in growth of plants in Sphagnum with the roots sub- 
merged is greater than under similar conditions in peat. This appears to be due for the most part to a greater lack of oxygen in Sphagmum than in peat. A similar relation exists between plants in peat and in soil with the roots submerged.

(4) When the water is aerated plants, are able to endure root submergence as long as aeration is maintained. The roots show some retardation in growth, but remain alive.

(5) Ramunculus abortivus, $R$. sceleratus, and Cyperus alternifolius grown in submerged soil show a greater growth of the entire plant than when grown in moist soil. The ability to grow with the roots submerged is undoubtedly due to the presence of aerenchyma. The reduction of the growth of the plants in moist soil is caused by the inability of the roots to absorb sufficient water under such conditions.

(6) Land plants with submerged roots show more or less pronounced wilting after one to three days. If submergence is prolonged the leaves become yellow and soon fall.

(7) Land plants with submerged roots do not show these effects, or only to a slight extent, in aerated water.

(8) Philotria placed in water with good light causes a decrease in carbon dioxide and an increase in oxygen content of the water.

(9) Plants in soil from which oxygen is excluded show wilting, etiolation, and loss of leaves. The effects appear in the same order and same time as in plants with the roots submerged.

(I0) Plants with submerged roots show a temporary increase in transpiration, which is soon followed by a sharp decline as compared with the transpiration of plants grown in moist soil.

(I I) The reduction in transpiration precedes wilting. It precedes etiolation and loss of leaves by two to four days. This indicates that absorption is reduced below the amount demanded by transpiration.

(12) When aeration is provided, the development of plants is essentially as good with swamp water as with nutrient solution. Plants with swamp water are somewhat smaller. The difference is somewhat more evident when the plants are deprived of reserve food. This indicates that the difference in growth is correlated with the food supply.

(I3) The oxygen content of lake water is essentially the same as that of tap or distilled water under similar conditions. The oxygen content of swamp water decreases from the Carex stage to the Chamaedaphne-Andromeda and Larix-Picea stages.

(14) The carbon dioxide content shows a corresponding increase through the same stages. The increase is due to the decomposition of organic matter by which carbon dioxide is liberated.

(I5) The adjustment of the roots of swamp plants to the water-level is due to the necessity of securing a sufficient supply of oxygen. This 
necessity is met by structural modifications or merely by a change in the level at which the roots develop.

(16) The presence of hydrophytes, mesophytes, and xerophytes in swamps is due to local differences in the habitat. These differences, according to the nature of the adjustment of the roots to the water-level which influences the amount of water available, affect the ratio of absorption to transpiration and determine the character of the plant.

(I7) Ecesis is possible for many plants even when submerged. Ecesis can occur only when the oxygen requirements are satisfied.

The writer wishes to express his sincere thanks to Dr. F. E. Clements, who was at the time Head of the Department of Botany at the University of Minnesota, for many helpful criticisms and suggestions. Thanks are also due to Dr. I. H. Derby, of the School of Chemistry, University of Minnesota, for criticisms and suggestions on the chemical work in connexion with gas analysis.

\section{BIBLIOGRAPHY.}

1. Arker, J.: Die Beeinflussung des Wachstums der Wurzeln durch das umgebende Medium. Inaug. Diss., 1900.

2. Birge, E. A., and JunAy, C.: The Inland Lakes of Wisconsin : the Dissolved Gases of the Water and their Biological Significance. Wis. Geol. and Nat. Hist. Survey, vol. xxii, I9I I.

3. Boussingault, J. B., and Lewy: Mémoire sur la composition de l'air confiné dans la terre végétale. Annales de Chimie et de Physique, xxxvii, 3 rd series, p. 5, I 853 .

4. Cannon, W. A., and Free, E. E. : The Ecological Significance of Soil Aeration. Science, N.S., xlv. 178,1917 .

5. Dachnowski, A.: Peat Deposits of Ohio. Geol. Survey of Ohio, Bull. i6, i9i 2.

6. Dehérain, P. P., and Vesque, J. : Recherches sur la respiration des racines. Ann. Sci. Nat., Bot., Ser. 6, iii. 327,1876 .

7. Fodor, L. von: Experimentelle Untersuchungen über Boden und Bodengase. Deutsche Vierteljahrschrift für öffentliche Gesundheitspflege, vii. 205,1875 .

8. Gates, F. C. : Winter as a Factor in the Xerophily of certain Evergreen Ericads. Bot. Gaz., lvii. 445, I9 4 .

9. GLüCK, H. : Biologische und morphologische Untersuchungen über Wasser- und Sumpfgewächse, I905, I906, I9I I.

10. Groom, P.: Remarks on the Ecology of Coniferae. Annals of Botany, xxiv. 24I, I9 Io.

11. Hall, A. D., Brenchley, W. E., and Underwood, L. M. : The Soil Solutions and the Mineral Constituents of the Soil. Journ. Agric. Sci., vi. 278, I914. Reprinted from Phil. Trans., B, vol. cciv, I9I3.

12. Hole, R. S.: Oecology of Sal (Shorea robusta). Indian Forest Records, vol. v, Part IV.

13. Kraus, A. : Beiträge zur Kenntniss der Keimung und ersten Entwicklung von Landpflanzen unter Wasser. Inaug. Diss., Kiel, I90т.

14. Livingston, B. E., and Free, E. E.: The Effect of Deficient Soil Oxygen on the Roots of Higher Plants. Johns Hopkins Univ. Circular, p. I82, I 9 I 7 .

15. Lunge, G. : Technical Gas Analysis, I9I6.

16. MER, E. : Recherches expérimentales sur les conditions de développement des poils radicaux. Compt. rend., lxxxviii. $66_{5}, 1879$. 
17. Perseke, R.: Über die Formveränderung der Wurzel in Erde und Wasser. Inaug. Diss., Leipzig, $\mathbf{1} 877$.

18. Russell, E. J., and Appleyard, A.: The Atmosphere of the Soil: its Composition and the Causes of Variation. Journ. Agric. Sci., vii. I, I9I5.

19. Sachs, J. : Über das Wachstum der Haupt- und Nebenwurzeln. Arbeiten des botan. Instituts Würzburg, Bd. i, Heft 3, p. 407, I873.

20. - Die Wurzelhaare der Pflanzen. Untersuchungen aus dem botan. Inst. zu Tübingen, i. $135, \mathbf{1} 883$.

21. Sampson, A. W., and Allen, L. M : Influence of Physical Factors on Transpiration. Minn. Bot. Stud., vol. iv, p. 33, I909.

22. Schwartz, F. : Die Wurzelhaare der Pflanzen. Breslau, I883.

23. Sherff, E. E. : Vegetation of Skokie Marsh. Bot. Gaz., liii. 4I 5, I9I 2.

24. Vöchting, H. : Über die Keimung der Kartoffelknollen. Bot. Zeit., 1x. 87, I902.

25. WACKER, J.: Die Beeinflussung des Wachstums der Wurzeln durch das umgebende Medium. Jahrb. für wissensch. Bot., xxxii. 7I, I 898.

26. Wieler, A. : Die Beeinflussung des Wachsens durch verminderte Partiärpressung des Sauerstoffs. Untersuchungen aus dem botan. Inst. zu Tübingen, Bd. i, Heft. 2, p. I 89, I 883 .

27. YAPP, R. H.: Stratification in Vegetation of a Marsh and its Relations to Evaporation and Temperature. Annals of Botany, xxiii. 275, 1909. 


\section{$2 \mathrm{BHL}$ Biodiversity Heritage Library}

Bergman, H. F. 1920. "The relation of aeration to the growth and activity of roots and its influence on the ecesis of plants in swamps." Annals of botany 34, 13-33. https://doi.org/10.1093/aob/os-34.1.13.

View This Item Online: https://www.biodiversitylibrary.org/item/236972

DOI: https://doi.org/10.1093/aob/os-34.1.13

Permalink: https://www.biodiversitylibrary.org/partpdf/320273

\section{Holding Institution}

Smithsonian Libraries

\section{Sponsored by}

Biodiversity Heritage Library

\section{Copyright \& Reuse}

Copyright Status: Not in copyright. The BHL knows of no copyright restrictions on this item.

This document was created from content at the Biodiversity Heritage Library, the world's largest open access digital library for biodiversity literature and archives. Visit BHL at https://www.biodiversitylibrary.org. 